\title{
Degradation Kinetics of Fe-EDTA in Hydrogen Sulfide Removal Process
}

\author{
R. Saelee and C. Bunyakan \\ Pollutant Treatment Technology Research Unit, Department of Chemical Engineering, Faculty of Engineering, \\ Prince of Songkla University, Hat Yai, Songkhla 90112, Thailand \\ Correspondence should be addressed to C. Bunyakan, charun.b@psu.ac.th
}

Received 26 January 2012; Accepted 26 February 2012

Academic Editors: C. Chen and H. Domínguez

Copyright ( $) 2012$ R. Saelee and C. Bunyakan. This is an open access article distributed under the Creative Commons Attribution License, which permits unrestricted use, distribution, and reproduction in any medium, provided the original work is properly cited.

\begin{abstract}
Available data on the degradation of Fe-EDTA liquid redox $\mathrm{H}_{2} \mathrm{~S}$ removal processes are reviewed, and the effect of $\mathrm{H}_{2} \mathrm{~S}$ molar flow rate, the initial concentration of $\mathrm{Fe}$ (III)EDTA, and the presence of sodium citrate in Fe-EDTA solution were investigated in this study. The semibatch with continuous flow of $\mathrm{H}_{2} \mathrm{~S}$ containing biogas was used under a wide range of experimental conditions; $\mathrm{pH}=7.0, \mathrm{H}_{2} \mathrm{~S}$ molar flow rate, $Q_{\mathrm{H}_{2} \mathrm{~S}}\left(1.08 \times 10^{-3}-3.40 \times 10^{-3} \mathrm{~mol} / \mathrm{h}\right)$, the initial concentration of Fe(III)EDTA, $C_{\mathrm{Fe}, 0}(2.17-$ $\left.8.16 \mathrm{~mol} / \mathrm{m}^{3}\right)$, and the concentration of sodium citrate, $C_{C I}\left(0-300 \mathrm{~mol} / \mathrm{m}^{3}\right)$. The result showed that sodium citrate acted as stabilizer with a good ability to reduce the degradation rate. The degradation rate of Fe-EDTA was found to follow pseudo firstorder kinetics. Empirical correlations expressed the degradation rate constant as a function of significant $\mathrm{H}_{2} \mathrm{~S}$ molar flow rate, and the initial $\mathrm{Fe}$ (III)EDTA and sodium citrate concentration were successfully developed for the prediction of Fe-EDTA degradation rate. Moreover, the precipitated solid, called sulfur cake, was recovered, and its composition was investigated. The result revealed that the sulfur cake contained more than $98 \%$ sulfur element and almost balances with iron, and no significant EDTA was degraded into the solid form.
\end{abstract}

\section{Introduction}

The polyamino polycarboxylate-chelated iron process is extremely effective and allows total conversions of hydrogen sulfide to be obtained. It is also a very flexible process and has in fact been widely diffused throughout the world. This process, however, has various drawbacks. Above all, when operating in an alkaline solution, there is the radical oxidation of the iron ligand with the degradation of the ligand itself and the precipitation of iron as sulfide. This has two strong consequences on the process: the ligand, which is expensive, must be continuously reintegrated; furthermore, the sulfur produced is impure of iron sulfide, and this makes it absolutely unsuitable for commercialization. In practice, the lost of the chelating agents turns out to be the most significant factor affecting the economic feasibility of large scale operation.

A few of the prior art workers have acknowledged that chelated iron solutions are unstable and that undesirable precipitation of iron compounds may occur. Nichol and Sapiro $[1,2]$ recommended careful control of the regeneration of the catalyst solution to avoid overoxidation of the iron chelate. Thompson [3] indicates that restricting the molar ratio of chelating agent to iron is an important consideration in avoiding breakdown of the chelate molecule. Lynn and Dubs [4] suggest the addition of selected amine salt stabilizers to achieve chelate stability at low $\mathrm{pH}$ levels. Diaz [5-7] and Blytas [8] propose the addition of various sulfur-containing and nitrogen-containing compounds as stabilizers to reduce the rate of chelate degradation. Bedell [9] disclosed that soluble chemical compounds having a high affinity for hydroxyl radicals are effective stabilizers for chelating agents used in the hydrogen sulfide removal process. The researcher exposed the aromatic compounds that can further retard the degradation of the original metal chelate solution by reducing the amount of free hydroxyl radicals in the solution and by later complexing with metal ions released by degraded chelating agents before the 
aromatic compounds are degraded by additional hydroxyl radicals. Preferred compounds can be selected based upon solubilities, costs, and relative effectiveness. These prior arts have not provided an effective, environmentally acceptable, and inexpensive solution to the problem of chelate degradation. Moreover, there has been no adequate explanation of the mechanism of chelate instability in a hydrogen sulfide removal process. Until Chen et al. $[10,11]$ observed that polyaminocarboxylic acid trends to rupture at the weak locations, for example, ethylene moiety of EDTA which leads to dechelation and then degradation of Fe-EDTA. Cleavage is presumably ascribed to the presence of hydroxyl-free radicals produced from the reoxidation of ferrous chelate product into active ferric chelate via a Fenton mechanism.

Mcmanus and Kin [12] studied the effectiveness of sodium thiosulfate as a stabilizing additive in an aqueous NTA-iron chelate solution when used in a cyclic hydrogen sulfide removal catalyst regeneration process. The result showed the NTA concentration changed from $10.09 \mathrm{~g} / \mathrm{L}$ to $8.73 \mathrm{~g} / \mathrm{L}$ (a decrease of $13.5 \%$ ) in 92.5 hours, whereas in the control run the NTA was totally degraded shortly after 47 hours. The soluble Fe changed from 990 to $900 \mathrm{~g} / \mathrm{L}$ (10\%) in the presence of sodium thiosulfate whereas in the control run the soluble Fe concentration decreased about $30 \%$ within 92.5 hours.

Sunda and Huntsman [13] investigated that temperature, $\mathrm{pH}$, and light had also effect on equilibrium dissociation constant for Fe-EDTA chelates, which indicates the strength of binding between Fe and EDTA. They found that increases in $\mathrm{pH}$ (7.7-9) increased equilibrium dissociation constants for Fe-EDTA chelates, apparently due to the formation of mixed EDTA-hydroxy chelates. Light also increased the dissociation constant due to photoreductive dissociation of ferric-EDTA chelates. A decrease in temperature from 20 and $10^{\circ} \mathrm{C}$ had little effect on dissociation constants in the dark, indicating that rate constants for Fe-EDTA association and dissociation were about equally affected by temperature.

More recently, de Algelis et al. [14] studied the oxidation of hydrogen sulfide to sulfur by mean of treatment with an aqueous acid solution containing trivalent iron and a hetero polyacid. The oxidation cycle of hydrogen sulfide to sulfur (10 hours), filtration of the sulfur, and re-oxidation of the solution with air (4 hours) was repeated four times, on the same solution. They found that no decrease in the catalyst performance. However, the preparation of this oxidation solution is very complex.

To our knowledge, no kinetics study has been done on the degradation of Fe-EDTA in $\mathrm{H}_{2} \mathrm{~S}$ removal system, and no Fe-EDTA degradation rate equation has been presented. The prediction of the extent and rate of Fe-EDTA (or $\mathrm{Fe}$ (total)-EDTA) degradation is vital in the estimation of the exact $\mathrm{Fe}$ (III)EDTA make-up rate needed to maintain the $\mathrm{H}_{2} \mathrm{~S}$ absorption capacity of the removal process. The goal of this research was to determine the potential for FeEDTA degradation as a function of degradation parameters such as the $\mathrm{H}_{2} \mathrm{~S}$ molar flow rate, the initial Fe(III)EDTA concentration, and the concentration of the new stabilizer which were investigated in this study based on the initial FeEDTA degradation rate.

\section{Materials and Method}

2.1. Chemical. $40 \% \mathrm{w} / \mathrm{w}$ Ferric chloride solution $\left(\mathrm{FeCl}_{3}\right)$ and EDTANa $4 \cdot 4 \mathrm{H}_{2} \mathrm{O}$ powder with commercial grade were purchased from L.B. Science LTD, Thailand. Sodium thiosulfate $5 \cdot \mathrm{H}_{2} \mathrm{O}(99.5 \%$, Ajax Finechem) and sodium citrate $(99.0 \%$, Ajax Finechem) were used. Biogas (1, 300-1, 600 ppm $\mathrm{H}_{2} \mathrm{~S}$ content) produced from Mongkol pig farming located at Phattalung province was used in this study.

A Fe(III)EDTA solution was prepared using the following recipe. A $187 \mathrm{~g}$ of EDTA-4Na powder was dissolved into $900 \mathrm{~mL}$ of water wherein $100 \mathrm{~mL}$ of $40 \% \mathrm{FeCl}_{3}$ solution was added. The Fe(III)EDTA solution was obtained with the concentration of $0.35 \mathrm{~mol} \mathrm{Fe} / \mathrm{L}$. And the mole ratio of iron and EDTA in the solution was $1: 1.2$. Working solution for experiments was freshly prepared with deionized water. The calculated stabilizers amount was mixed with the $0.35 \mathrm{~mol}$ $\mathrm{Fe} / \mathrm{L}$ Fe-EDTA solution to obtain the expected concentration. The solution was adjusted to $\mathrm{pH} 7.0$ by adding $3 \mathrm{~N} \mathrm{HCl}$.

2.2. Experimental Procedure. The oxidation reaction of $\mathrm{H}_{2} \mathrm{~S}$ by $\mathrm{Fe}(\mathrm{III}) \mathrm{EDTA}$ in the presence and absence of the stabilizers was performed in the $1000 \mathrm{~mL}$ semibatch reactor where the biogas was continuously fed into liquid Fe-EDTA solution as illustrated in Figure 1. From Figure 1 the gas phase, biogas, and air were introduced separately as bubble into the $750 \mathrm{~mL}$ of predetermined concentration Fe(III)EDTA solution. Air flow rate used in all experiments was $1 \mathrm{~L} / \mathrm{min}$ throughout the reaction in order to reoxidize ferrous into the active ferric form. The ferrous regeneration efficiency was more than $90 \%$ in all experiments. The biogas volumetric flow rate was varied between 0.5 and $2.0 \mathrm{~L} / \mathrm{min}$. As Fe-EDTA degradation is a very slow process, each experiment requires a long experimentation time of $30 \mathrm{~h}$. During the experiment, the gas and liquid samples were collected at every $3 \mathrm{~h}$. To ensure actual representation of samples collected at each time interval, the gas introduction and sample removal dip tube was first rinsed to get rid of the old sample left in the tube from the last sample collection. The $\mathrm{H}_{2} \mathrm{~S}$ concentrations in biogas were determined at the inlet and the outlet of reactor by iodometric method. Because of the ferric in the form of ion in solution, it can oxidize $\mathrm{H}_{2} \mathrm{~S}$ to the element sulfur. Thus, the degradation of Fe-EDTA is the abatement of iron concentration in the solution. The concentration of soluble $\mathrm{Fe}$ in the solution was determined using atomic absorption spectroscopy. All experiments were performed at ambient temperature of $30 \pm 2^{\circ} \mathrm{C}$.

After $30 \mathrm{~h}$ of reaction time the solid product was filtered, washed, dried, and analyzed with CHNS-analyzer to determine $\%$ weight of carbon, hydrogen, nitrogen, and sulfur element.

\section{Results and Discussion}

3.1. Degradation of Fe-EDTA Kinetics Studies. The rate equation was formulated based on the assumption that $\mathrm{Fe}$ (III)EDTA reacted only in the liquid phase with dissolved $\mathrm{H}_{2} \mathrm{~S}$, which allowed the degradation kinetics to be formulated as a homogeneous liquid phase system. Although 


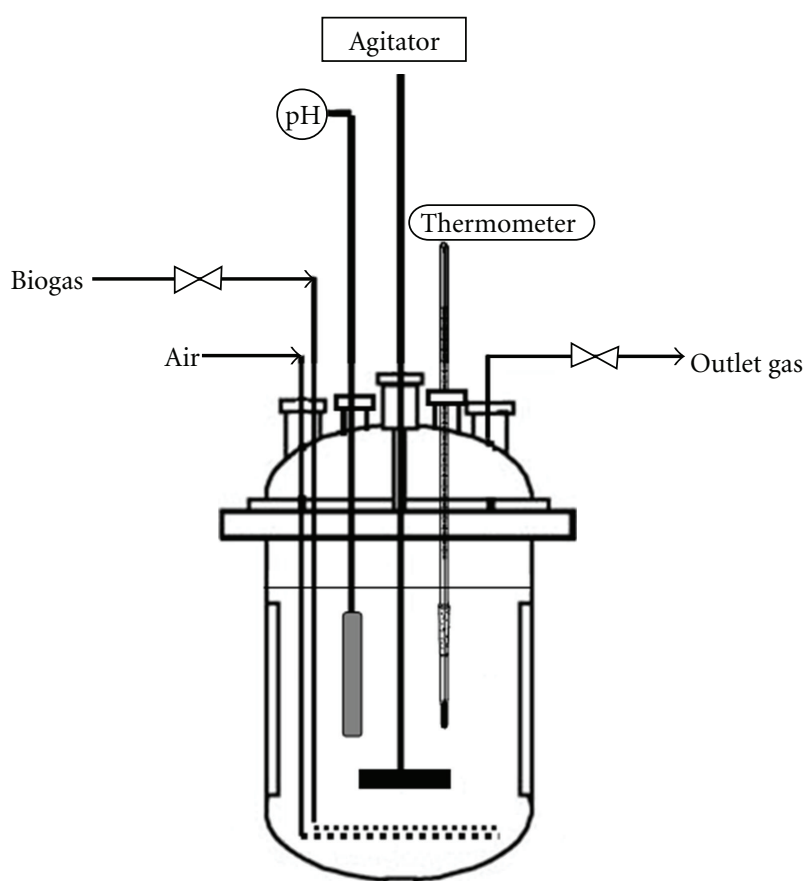

Figure 1: The semibatch system.

mass transfer could possibly control the degradation rate of $\mathrm{H}_{2} \mathrm{~S}$, the mass transfer limitation is insignificant during the degradation time (e.g., $0-30 \mathrm{~h}$ of degradation time) since an appropriate stirring speed is applied [15]. The interference from degradation products could also be neglected. These assumptions were used to formulate the kinetic model in this study.

Figures 2 and 3 represent soluble Fe concentration versus time relationship which indicates a first approach. Thus, the degradation of Fe-EDTA can be described by pseudo firstorder kinetics with respect to Fe concentration as expressed in the following equation:

$$
R_{d}=-\frac{d C_{\mathrm{Fe}}}{d t}=k_{d} C_{\mathrm{Fe}}
$$

Separating and integrating (1), we obtain the following:

$$
-\ln \left(\frac{C_{\mathrm{Fe}, t}}{C_{\mathrm{Fe}, 0}}\right)=k_{d} t
$$

where $R_{d}$ represents the Fe-EDTA degradation rate, $k_{d}$ represents the pseudo first-order degradation rate constant, $C_{\mathrm{Fe}, 0}$ and $C_{\mathrm{Fe}, t}$ represent the concentration of soluble $\mathrm{Fe}$ at an initial and at any reaction time, respectively. In this case, a plot of $-\ln \left(C_{\mathrm{Fe}, t} / C_{\mathrm{Fe}, 0}\right)$ versus time in every experiment must lead to a straight line with slope of $k_{d} . k_{d}$ may be a function of several variables as follows:

$$
k_{d}=\mathrm{fn}\left(Q_{\mathrm{H}_{2} \mathrm{~S}}, C_{\mathrm{Fe}, 0}, C_{\mathrm{CI}}, \ldots\right),
$$

where $Q_{\mathrm{H}_{2} \mathrm{~S}}$ represents $\mathrm{H}_{2} \mathrm{~S}$ molar flow rate, and $C_{\mathrm{CI}}$ represents the concentration of sodium citrate.

The effect of $\mathrm{H}_{2} \mathrm{~S}$ molar flow rate was evaluated by using $5.78 \mathrm{~mol} / \mathrm{m}^{3}$ initial $\mathrm{Fe}(\mathrm{III})$ EDTA concentration, while the

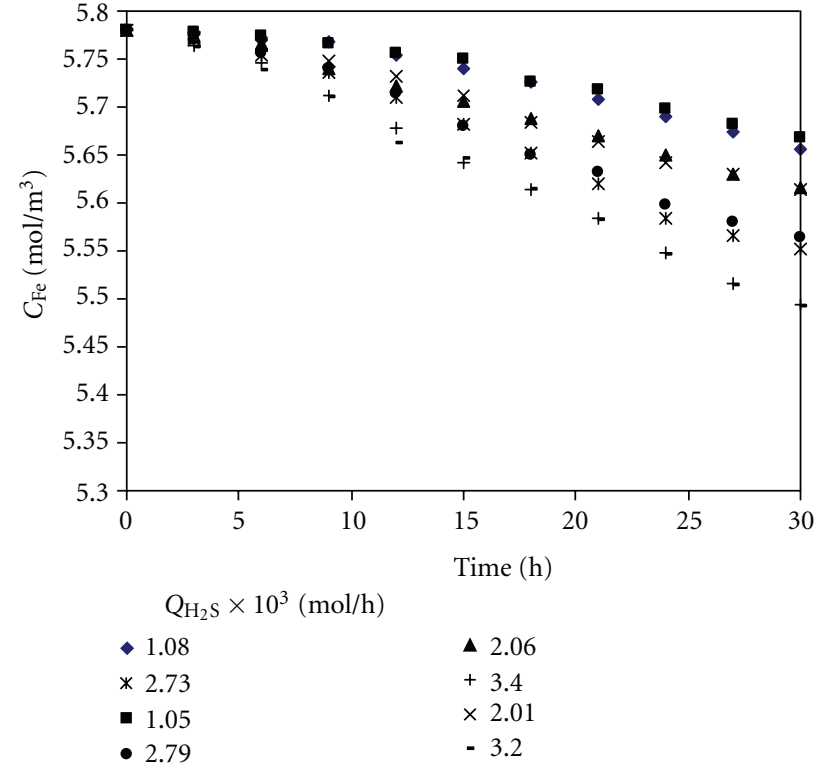

Figure 2: Soluble Fe concentration $\left(C_{\mathrm{Fe}}\right)$ time of various $\mathrm{H}_{2} \mathrm{~S}$ molar flow rate $\left(Q_{\mathrm{H}_{2} \mathrm{~S}}\right)$ at initial $\mathrm{Fe}(\mathrm{III}) \mathrm{EDTA}$ concentration $\left(C_{\mathrm{Fe}, 0}\right)$ of $5.78 \mathrm{~mol} / \mathrm{m}^{3}$.

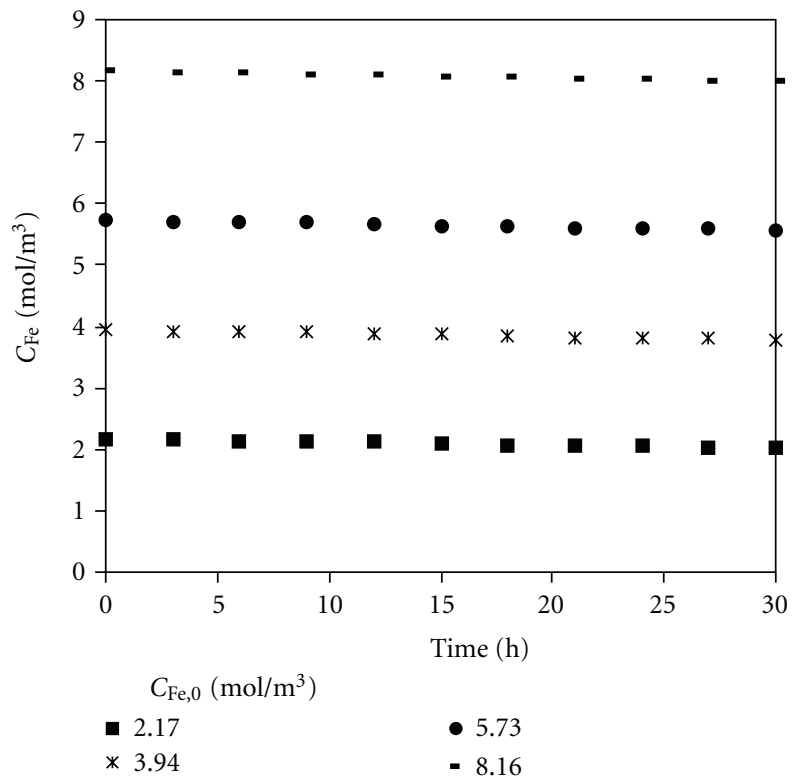

FIGURE 3: Soluble Fe concentration $\left(C_{\mathrm{Fe}}\right)$ time of various initial $\mathrm{Fe}(\mathrm{III})$ EDTA centration $\left(C_{\mathrm{Fe}, 0}\right)$ at the $\mathrm{H}_{2} \mathrm{~S}$ molar flow rate $\left(Q_{\mathrm{H}_{2} \mathrm{~S}}\right)$ of $2.0 \times 10^{-3} \mathrm{~mol} / \mathrm{h}$.

average $\mathrm{H}_{2} \mathrm{~S}$ molar flow rate of $2.0 \times 10^{-3} \mathrm{~mol} / \mathrm{h}$ was used to study the effect of the initial $\mathrm{Fe}$ (III)EDTA concentration. The Fe-EDTA degradation rates $\left(R_{d}\right)$ of each experimental run are listed in Table 1 . It can be observed that $R_{d}$ increases rapidly with increasing $Q_{\mathrm{H}_{2} \mathrm{~S}}$, but it only slightly decreases with increasing $C_{\mathrm{Fe}, 0}$. This can conclude that the effect of $Q_{\mathrm{H}_{2} \mathrm{~S}}$ on $R_{d}$ is greater than the effect of $C_{\mathrm{Fe}, 0}$.

This result is consistent with Chen et al. [10] who observed that the iron chelate degradation occurs during 
TABLE 1: Fe-EDTA degradation rate $\left(R_{d}\right)$ at various $\mathrm{H}_{2} \mathrm{~S}$ molar flow rate $\left(Q_{\mathrm{H}_{2} \mathrm{~S}}\right)$ and initial $\mathrm{Fe}(\mathrm{III})$ EDTA concentration $\left(C_{\mathrm{Fe}, 0}\right)$.

\begin{tabular}{lccc}
\hline Run no. & $\begin{array}{c}\left(\mathrm{Q}_{\mathrm{H}_{2} \mathrm{~S}}\right) \times 10^{3} \\
(\mathrm{~mol} / \mathrm{h})\end{array}$ & $C_{\mathrm{Fe}, 0}\left(\mathrm{~mol} / \mathrm{m}^{3}\right)$ & $\begin{array}{c}R_{d} \\
\left(\mathrm{~mol} \mathrm{~m}^{-3} \mathrm{~h}^{-1}\right)\end{array}$ \\
\hline 1 & 1.08 & 5.78 & 0.00356 \\
2 & 1.05 & 5.78 & 0.00323 \\
3 & 2.06 & 5.78 & 0.00528 \\
4 & 2.01 & 5.78 & 0.00535 \\
5 & 2.73 & 5.78 & 0.00746 \\
6 & 2.79 & 5.78 & 0.00707 \\
7 & 3.40 & 5.78 & 0.00939 \\
8 & 3.20 & 5.78 & 0.00950 \\
9 & 1.79 & 2.17 & 0.00493 \\
10 & 1.81 & 2.17 & 0.00508 \\
11 & 1.94 & 3.94 & 0.00511 \\
12 & 1.90 & 3.94 & 0.00515 \\
13 & 2.16 & 5.73 & 0.00556 \\
14 & 2.13 & 5.73 & 0.00539 \\
15 & 2.37 & 8.16 & 0.00556 \\
16 & 2.40 & 8.16 & 0.00514 \\
\hline
\end{tabular}

the re-oxidation of the ferrous to ferric system with air (molecular oxygen). They suggested that only free radicals have enough energy to degrade these chelating ligands which lead to dechelation (degradation) of iron chelate and also indicates that the hydroxyl radical may be formed under the reaction conditions.

The main degradation products identified by Chen et al. [11] are iminodiacetic acid (IDA) and ethylenediaminediacetic acid (EDDA). All of the oxidation intermediates being formed by hydroxylation of one of the $\mathrm{CH}_{2}$ groups, either on the ethylene bridge or side chain acetate groups. Following hydroxylation, the aldehyde formed by hydrolytic cleavage is rapidly converted to the corresponding carboxylate. It is worth noting that the $\mathrm{pH}$ in all the experiments decreased during the reaction going from 7.0 to 4.5. Under this acidic condition the $\mathrm{Fe}$-chelated degradation rate can also be slightly promoted [10].

All results can be described by the pseudo first-order kinetics as evident by the plot of $-\ln \left(C_{\mathrm{Fe}, t} / C_{\mathrm{Fe}, 0}\right)$ versus time as illustrated in Figures 4 and 5. It can be observed in these figures that the linear relationship between $-\ln \left(C_{\mathrm{Fe}, t} / C_{\mathrm{Fe}, 0}\right)$ and time was highly with the coefficients of determination greater than 0.91. In experiments carried out in duplicate as can be seen in Figures 6 and 7, the pseudo first-order rate constant, $k_{d}$, with respect to $\mathrm{H}_{2} \mathrm{~S}$ molar flow rate $\left(\mathrm{Q}_{\mathrm{H}_{2} \mathrm{~S}}\right)$ and initial $\mathrm{Fe}(\mathrm{III}) \mathrm{EDTA}$ concentration $\left(C_{\mathrm{Fe}, 0}\right)$, respectively, varied by less than $10 \%$. The observed degradation rate constant, $k_{d}$ increase with increasing $\mathrm{H}_{2} \mathrm{~S}$ molar flow rate while the increasing of the initial Fe(III)EDTA concentration decrease $k_{d}$.

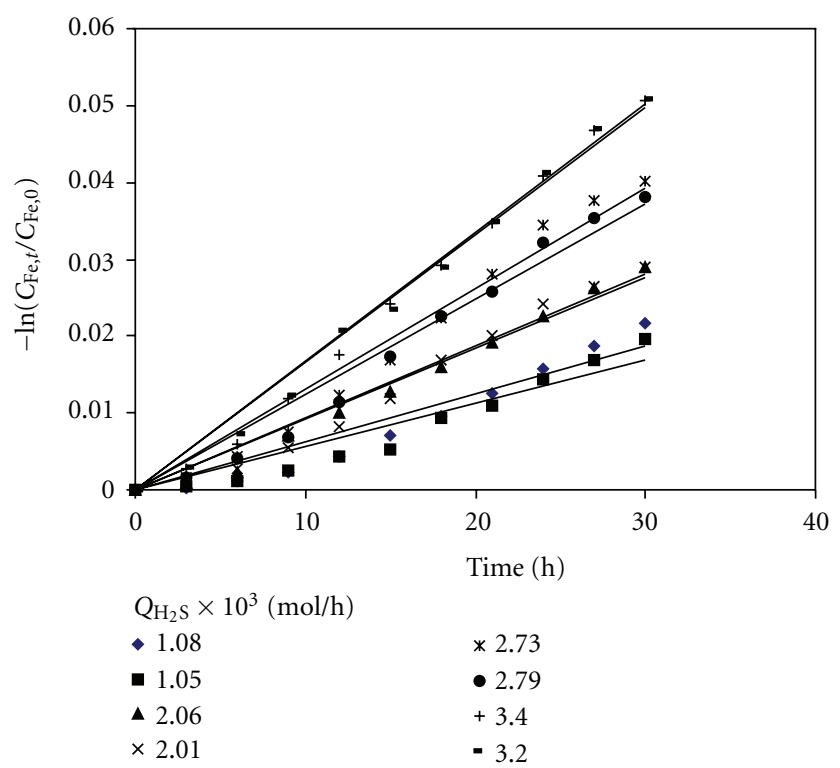

Figure 4: Effect of $\mathrm{H}_{2} \mathrm{~S}$ molar flow rate $\left(Q_{\mathrm{H}_{2} \mathrm{~S}}\right)$ on the degradation of $\mathrm{Fe}(\mathrm{III}) \mathrm{EDTA}$. First-order plots for $\mathrm{Fe}(\mathrm{III}) \mathrm{EDTA}$ degradation at the initial $\mathrm{Fe}(\mathrm{III}) \mathrm{EDTA}$ concentration of $5.78 \mathrm{~mol} / \mathrm{m}^{3}$.

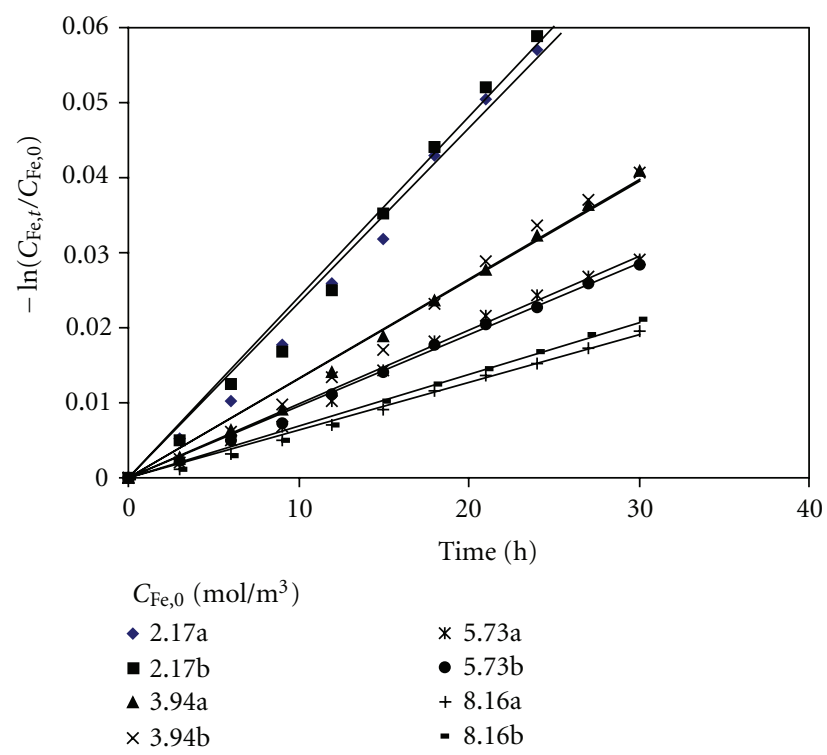

FIgure 5: Effect of initial Fe(III)EDTA concentration $\left(C_{\mathrm{Fe}, 0}\right)$ on the degradation of Fe(III)EDTA. First-order plots for Fe(III)EDTA degradation at the $\mathrm{H}_{2} \mathrm{~S}$ molar flow rate of $2.0 \times 10^{-3} \mathrm{~mol} / \mathrm{h}$.

The relationship between $k_{d}$ and $Q_{\mathrm{H}_{2} \mathrm{~S}}$ and $C_{\mathrm{Fe}, 0}$ was formulated using linear regression method. Result is given in the following equation:

$$
\begin{aligned}
k_{d}\left(Q_{\mathrm{H}_{2} \mathrm{~S}}, C_{\mathrm{Fe}, 0}\right)= & 3.446-0.784 C_{\mathrm{Fe}, 0}+0.0452 C_{\mathrm{Fe}, 0}^{2} \\
& +0.111 \times 10^{-3} Q_{\mathrm{H}_{2} \mathrm{~S}}^{2} .
\end{aligned}
$$

The empirical equation was evaluated based on the coefficient of determination value $R^{2}$ and adjusted $R^{2}$ of 0.982 and 0.978 , respectively. This indicated that there was 


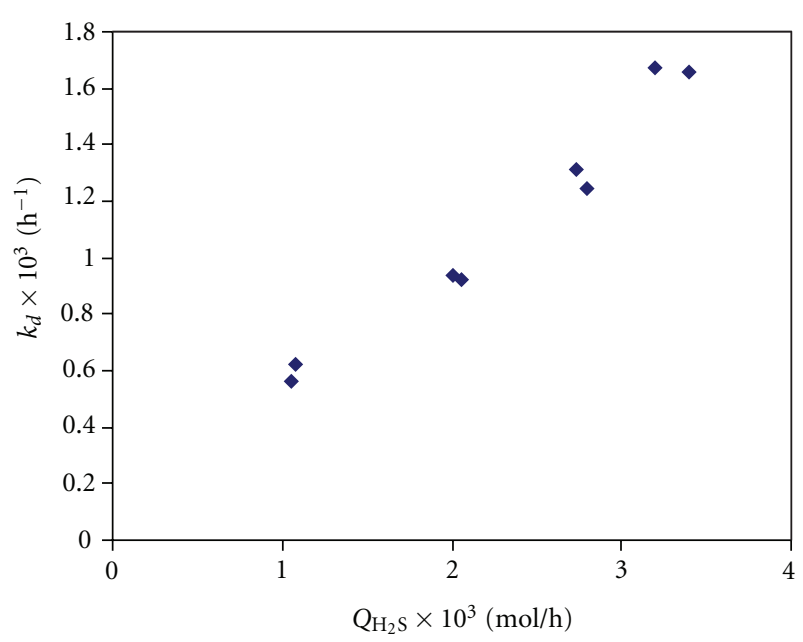

FIGURE 6: Effect of $\mathrm{H}_{2} \mathrm{~S}$ molar flow rate $\left(Q_{\mathrm{H}_{2} \mathrm{~S}}\right)$ on observed degradation rate constant $\left(k_{d}\right)$ at the initial $\mathrm{Fe}(\mathrm{III}) \mathrm{EDTA}$ concentration of $5.78 \mathrm{~mol} / \mathrm{m}^{3}$.

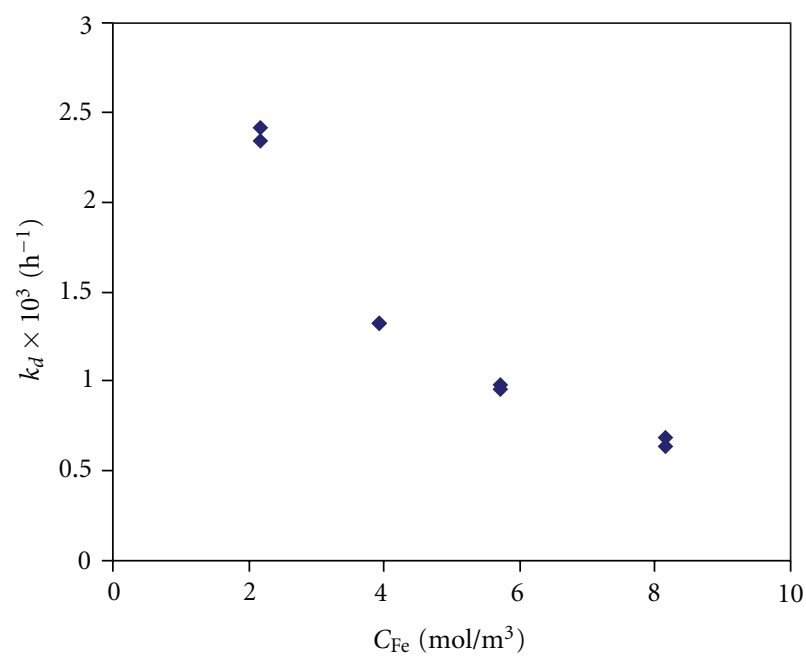

Figure 7: Effect of initial Fe(III)EDTA concentration $\left(C_{\mathrm{Fe}, 0}\right)$ on observed degradation rate constant $\left(k_{d}\right)$ at the average $\mathrm{H}_{2} \mathrm{~S}$ molar flow rate of $2.0 \times 10^{-3} \mathrm{~mol} / \mathrm{h}$.

a good agreement between the experimental and predicted $k_{d}$ value. A visual comparison of the model and experimental $k_{d}$ is shown in Figure 8.

Now, $k_{d}$ can be predicted from (4), and Fe-EDTA degradation rate $\left(R_{d}\right)$ was then calculated by multiplying $k_{d}$ and $C_{\mathrm{Fe}}$. The comparison between the calculated and the measured $R_{d}$ was made as given in Figure 9. It can be observed that they showed a good agreement in the proposed model of (1).

Thus, Fe-EDTA degradation rate $\left(R_{d}\right)$ calculated using $k_{d}$ from the empirical equation (4) was sufficient precision under a wide range of the experimental condition.

3.2. Analysis of Sulfur Cake. The species presented in the precipitate or sulfur cake from $\mathrm{H}_{2} \mathrm{~S}$ oxidation were identified

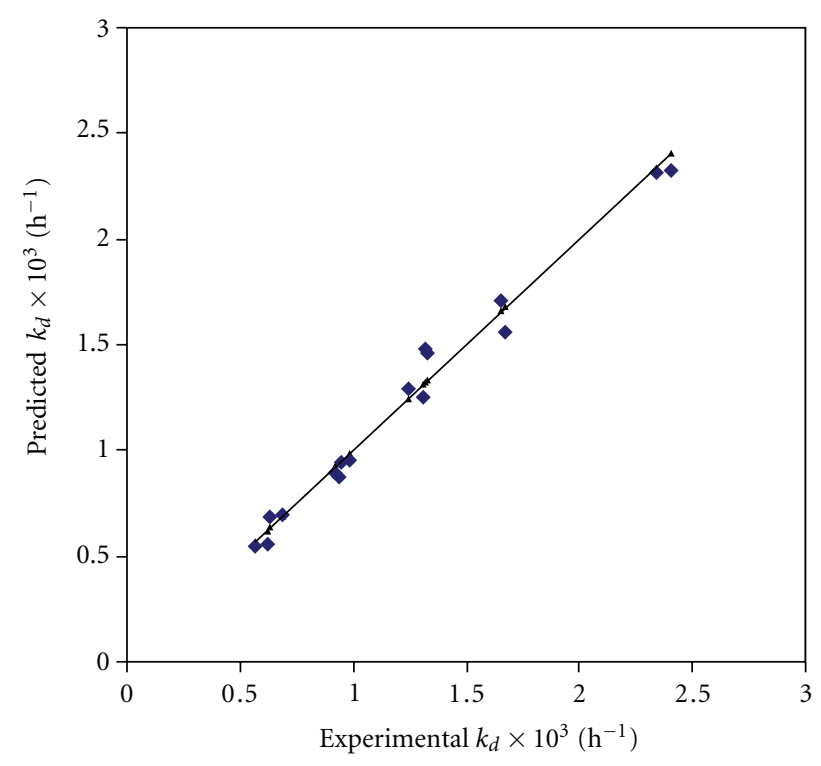

Figure 8: Plot of experimental and predicted $k_{d}$ (from (4)).

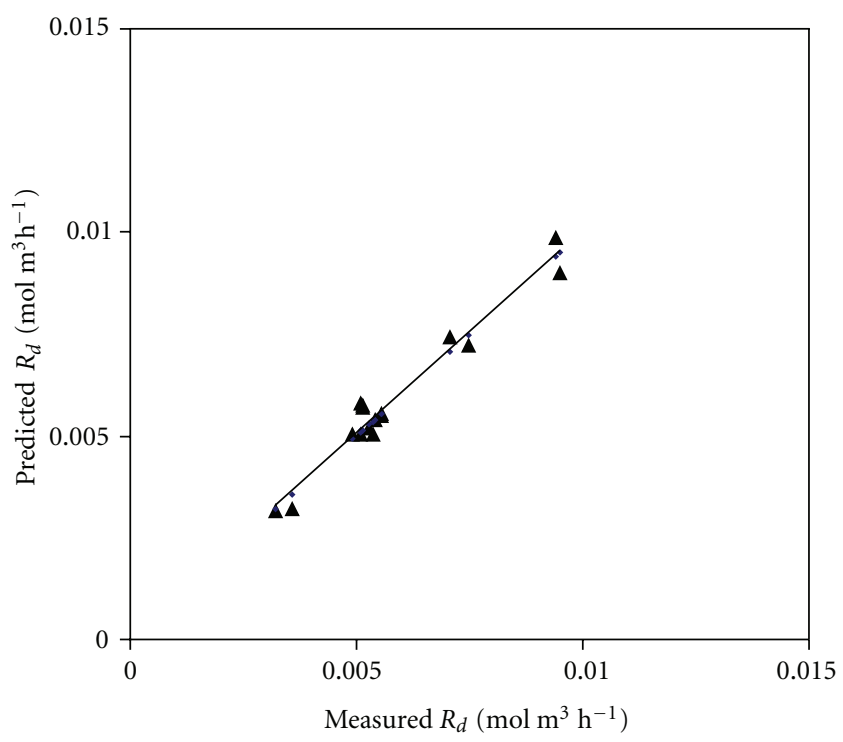

Figure 9: Plot of measured $R_{d}$ and predicted $R_{d}$ calculated using $k_{d}\left(Q_{\mathrm{H}_{2} \mathrm{~S}}, C_{\mathrm{Fe}, 0}\right)$ model.

in this studied. The main species that assume to be in the sulfur cake are $\mathrm{C}, \mathrm{H}, \mathrm{N}$, and $\mathrm{O}$ from EDTA degradation, $\mathrm{S}$ from $\mathrm{H}_{2} \mathrm{~S}$ oxidation, and $\mathrm{Fe}$ from Fe-EDTA dechelation. The CHNS analyzer and UV-VIS spectrophotometer (samples were treat treated by phenanthroline method) was used to analyze the quantity of $\mathrm{C}, \mathrm{H}, \mathrm{N}$, and $\mathrm{S}$ element, and $\mathrm{Fe}$, respectively. The analyzed sulfur cake result is shown in Table 2. The sum of amount of elements in sulfur cake showed a mass balance of about $100 \%$. As expected, S (more than $98 \%$ by weight) was the main element in the sulfur cake with small amount Fe and very small amount of $\mathrm{C}, \mathrm{H}$, and $\mathrm{N}$. The amount of Fe found in sulfur cake was almost consistent with $\mathrm{Fe}$ degraded from the solution. It can be noted that no 
significant EDTA degrades into the solid form. The remained EDTA and its ruptured products were still in the solution. However, the products cleavage from EDTA does not have high affinity enough to maintain $\mathrm{Fe}$ in the solution from.

\subsection{The Effect of Chemicals Additive into Fe-EDTA Solution.} $\mathrm{Fe}$ (III)EDTA is capable use for the oxidation of $\mathrm{H}_{2} \mathrm{~S}$ to element sulfur. The main difficulty with the process is the degradation of Fe-EDTA catalyst. The loss of Fe-EDTA is caused by the degradation of EDTA. Chen et al. [10] suggested that degradation is promoted by hydroxyl radicals. A number of additives that function as radical scavengers have been used to slow down radical induced oxidative degradation. There are many such additives that may be used. A very effective and inexpensive free radical scavenger is thiosulfate ion $\left(300 \mathrm{~mol} / \mathrm{m}^{3}\right)$, usually supplied as sodium thiosulfate. In this study, the common hydroxyl scavenger, sodium citrate was used. Citric acid and its salts have many applications in everyday life. Among others, it is used as an additive in food and in the production of cold drinks [16]. Many literatures reported that citrate has ability to reduce free radical formation $[17,18]$ and also is a ligand with high affinity complex with iron. The comparison of the capability to reduce Fe-EDTA degradation rate between using sodium citrate and sodium thiosulfate in this study is shown in Table 3. The result demonstrated that the effectiveness of sodium citrate as a stabilizer was slightly higher than sodium thiosulfate. A suitable stabilizer is required to reduce the degradation rate and keep the iron in solution. Sodium citrate was chosen as a stabilizer in this degradation kinetics study based on the following reasons. Using thiosulfate, the sulfur compounds in the system is raised that it can be converted to $\mathrm{H}_{2} \mathrm{~S}$ or other toxic compounds such as sulfite. This is not a problem of sodium citrate. The cost of citrate is lower than thiosulfate because sodium citrate can be produced from citric acid and sodium hydroxide which are cheap and commercial. Thus, sodium citrate is a suitable stabilizer for reducing the Fe-EDTA degradation rate.

3.4. The Effect of Sodium Citrate Concentration in Fe-EDTA Degradation. According to the previous section, sodium citrate is the suitable additive which can be used as stabilizer based upon the solubility, cost, and relative effectiveness. The experiments were set to determine the relationship of sodium citrate concentration $\left(C_{\mathrm{CI}}\right)$ and the Fe-EDTA degradation rate $\left(R_{d}\right)$. The experimental runs were conducted using the sodium citrate concentration of $0-300 \mathrm{~mol} / \mathrm{m}^{3}$ with the $\mathrm{H}_{2} \mathrm{~S}$ molar flow rate and the initial Fe(III)EDTA concentration of $1.84 \times 10^{-3} \mathrm{~mol} / \mathrm{h}$ and $5.80 \mathrm{~mol} / \mathrm{m}^{3}$, respectively.

Again, the degradation of Fe-EDTA followed by the first-order degradation rate as supported by the relationship between $-\ln \left(C_{\mathrm{Fe}, t} / C_{\mathrm{Fe}, 0}\right)$ and time which is shown in Figure 10 with the coefficients of determination value higher than 0.93 .

$k_{d}$ decreases with an increase in $C_{\mathrm{CI}}$ as illustrated in Figure 11. It is also observed that the reduction of $R_{d}$ may be constant as $C_{\mathrm{CI}}$ greater than that $300 \mathrm{~mol} / \mathrm{m}^{3}$. The relationship between $k_{d}$ and $C_{\text {CI }}$ up to $300 \mathrm{~mol} / \mathrm{m}^{3}$ was fitted.

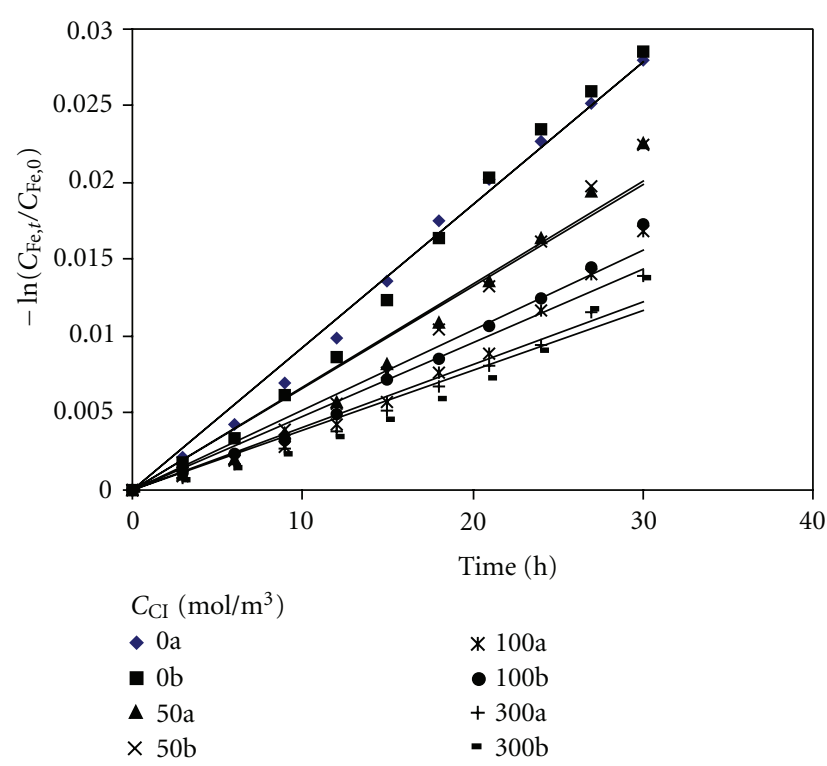

FIgURE 10: Effect of sodium citrate concentration $\left(C_{\mathrm{CI}}\right)$ on the degradation of $\mathrm{Fe}$ (III)EDTA. First-order plots for $\mathrm{Fe}$ (III)EDTA degradation at the $\mathrm{H}_{2} \mathrm{~S}$ molar flow rate of $1.84 \times 10^{-3} \mathrm{~mol} / \mathrm{h}$ and initial $\mathrm{Fe}$ (III)EDTA concentration of $5.80 \mathrm{~mol} / \mathrm{m}^{3}$.

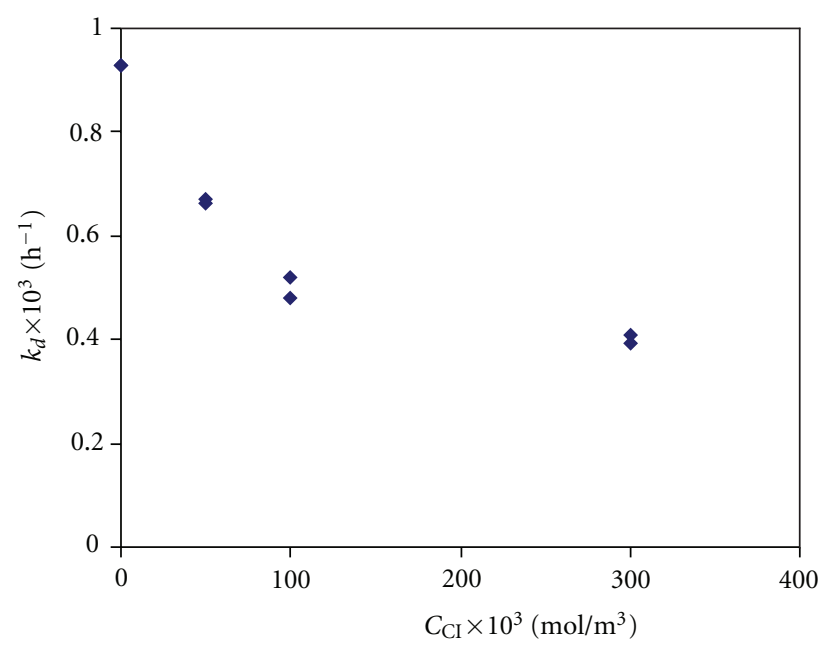

FIGURE 11: Effect of sodium citrate concentration $\left(C_{\mathrm{CI}}\right)$ on observed degradation rate constant $\left(k_{d}\right)$ at the average $\mathrm{H}_{2} \mathrm{~S}$ molar flow rate of $1.84 \times 10^{-3} \mathrm{~mol} / \mathrm{h}$ and initial $\mathrm{Fe}(\mathrm{III})$ EDTA concentration of $5.80 \mathrm{~mol} / \mathrm{m}^{3}$.

The empirical model with $R^{2}$ and adjusted $R^{2}$ of 0.983 and 0.976 , respectively, was obtained as given by the following equation:

$$
k_{d}\left(C_{\mathrm{CI}}\right)=0.921-0.00526 C_{\mathrm{CI}}+1.176 \times 10^{-5} C_{\mathrm{CI}}^{2} .
$$

It can be noted from (5) that the $k_{d}$ at the absence of sodium citrate was equal to $0.921 \mathrm{~h}^{-1}$. This value represents the effect of $Q_{\mathrm{H}_{2} \mathrm{~S}}$ and $C_{\mathrm{Fe}, 0}$ on the degradation of Fe-EDTA. Thus, the truly effect of $C_{C I}$ is just the last two terms of (5).

Moreover, the $k_{d}$ evaluated from slope of Figures 4, 5, and 10 at corresponding $Q_{\mathrm{H}_{2} \mathrm{~S}}, C_{\mathrm{Fe}, 0}$, and $C_{\mathrm{CI}}$ were together 
TABLE 2: The composition of sulfur cake for each sample.

\begin{tabular}{lcccccccc}
\hline $\begin{array}{l}\left(\mathrm{Q}_{\mathrm{H}_{2} \mathrm{~S}}\right) \times 10^{3} \\
(\mathrm{~mol} / \mathrm{h})\end{array}$ & $\begin{array}{c}C_{\mathrm{Fe}, 0} \\
\left(\mathrm{~mol} / \mathrm{m}^{3}\right)\end{array}$ & $\begin{array}{c}\text { Sulfur cake } \\
(\mathrm{g})\end{array}$ & $\mathrm{N}$ & $\mathrm{C}$ & $\mathrm{H}$ & $\mathrm{S}$ & $\mathrm{Fe}$ & Sum elements (wt) \\
\hline 1.08 & 5.78 & 0.805 & 0.19 & 0.96 & 0.12 & 98.36 & 0.40 & 100.03 \\
2.73 & 5.78 & 2.251 & 0.11 & 0.83 & 0.10 & 99.10 & 0.35 & 100.49 \\
3.20 & 5.78 & 2.675 & 0.12 & 0.68 & 0.08 & 99.01 & 0.56 & 100.45 \\
1.81 & 2.17 & 1.535 & $<0.01$ & 0.74 & 0.09 & 98.62 & 0.28 & 99.73 \\
1.94 & 3.94 & 1.693 & $<0.01$ & 0.72 & 0.08 & 98.97 & 0.24 & 100.01 \\
2.13 & 5.73 & 1.922 & $<0.01$ & 0.56 & 0.07 & 99.93 & 0.23 & 100.79 \\
2.40 & 8.16 & 2.106 & $<0.01$ & 0.59 & 0.07 & 99.23 & 0.32 & 100.21 \\
\hline
\end{tabular}

TAвLE 3: Fe-EDTA degradation rate $\left(R_{d}\right)$ with and without additive.

\begin{tabular}{|c|c|c|c|c|}
\hline$\left(Q_{\mathrm{H}_{2} \mathrm{~S}}\right) \times 10^{3}(\mathrm{~mol} / \mathrm{h})$ & $C_{\mathrm{Fe}, 0}\left(\mathrm{~mol} / \mathrm{m}^{3}\right)$ & Additive & $\begin{array}{l}\text { Additive concentration } \\
\qquad\left(\mathrm{mol} / \mathrm{m}^{3}\right)\end{array}$ & $R_{d}$ \\
\hline 1.07 & 5.84 & No additive & 0 & $0.00536 \pm 0.00001$ \\
\hline 2.04 & 5.85 & Sodium citrate & 300 & $0.00278 \pm 0.00012$ \\
\hline 2.41 & 5.70 & Sodium thiosulfate & 300 & $0.00322 \pm 0.00004$ \\
\hline
\end{tabular}

analyzed by linear regression method. The best fitted model with $R^{2}$ and adjusted $R^{2}$ of 0.986 and 0.982 is shown as follows:

$$
\begin{aligned}
k_{d}\left(Q_{\mathrm{H}_{2} \mathrm{~S}}, C_{\mathrm{Fe}, 0}, C_{\mathrm{CI}}\right)= & 3.429-0.773 C_{\mathrm{Fe}, 0} \\
& +0.0443 C_{\mathrm{Fe}, 0}^{2}+0.110 \times 10^{-3} \mathrm{Q}_{\mathrm{H}_{2} \mathrm{~S}}^{2} \\
& -0.00698 C_{\mathrm{CI}}+1.546 \times 10^{-5} C_{\mathrm{CI}}^{2} .
\end{aligned}
$$

It can be noticed that all terms in (4) and (5) are presented in (6) with quite same magnitude of coefficient except the intercept in (5). This supported the assumption above that the intercept in (4) is the effect from $Q_{\mathrm{H}_{2} \mathrm{~S}}$ and $C_{\mathrm{Fe}, 0}$ only. Thus, it can say that the equation of $k_{d}$ related to all parameters can be obtained by the summation of each (real) $k_{d}$ equation.

The $R_{d}$ calculated using the $k_{d}\left(Q_{\mathrm{H}_{2} \mathrm{~S}}, C_{\mathrm{Fe}, 0}, C_{\mathrm{CI}}\right)$, in (6) have a good agreement with the measured $R_{d}$ as demonstrated in Figure 12.

The concentration of Fe-EDTA at anytime in the reaction can be predicted by (7) which is rewriting from(2)

$$
C_{(\mathrm{Fe}, t)}=C_{(\mathrm{Fe}, 0)} e^{-k_{d} t},
$$

where $k_{d}$ can be calculated using (6).

Equation (7) is very useful in the $\mathrm{H}_{2} \mathrm{~S}$ removal by oxidation with $\mathrm{Fe}(\mathrm{III}) \mathrm{EDTA}$. When all parameters, $Q_{\mathrm{H}_{2} \mathrm{~S}}$, $C_{\mathrm{Fe}, 0}$, and $C_{\mathrm{CI}}$, are known, it can used to predict the concentration of Fe-EDTA at any interested time, so we can predict that how long the system still gave high efficiency and when the system needs to be made up with new Fe(III)EDTA solution.

\section{Conclusion}

The degradation rate of Fe-EDTA followed pseudo first order. The effect of $\mathrm{H}_{2} \mathrm{~S}$ molar flow rate, the initial

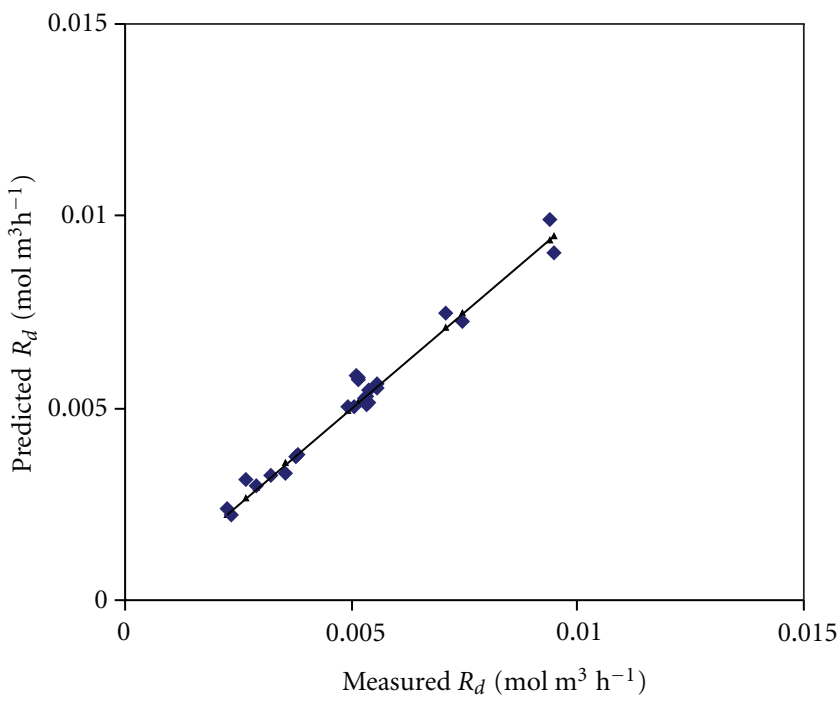

FIGURE 12: Plot of measured $R_{d}$ and predicted $R_{d}$ calculated using $k_{d}\left(Q_{\mathrm{H}_{2} \mathrm{~S}}, C_{\mathrm{Fe}, 0}, C_{\mathrm{CI}}\right)$ model.

$\mathrm{Fe}(\mathrm{III}) \mathrm{EDTA}$, and sodium citrate concentration were investigated, and the empirical correlations expressed the degradation rate constant as a function of significant $\mathrm{H}_{2} \mathrm{~S}$ molar flow rate, and initial Fe(III)EDTA and sodium citrate concentration were successfully developed. The result demonstrated that the degradation rate of Fe-EDTA in $\mathrm{H}_{2} \mathrm{~S}$ removal system could be predicted with sufficient precision via the developed correlation model. Sulfur cake was also recovered. It was found that the sulfur cake contained more than $98 \%$ sulfur element and almost balances with iron, and no significant EDTA was degraded into the solid form.

The kinetics knowledge obtained from this work can be used to develop the $\mathrm{H}_{2} \mathrm{~S}$ removal process from biogas or other gas stream, particularly the chemical quantity used in 
system. A kinetic evaluation also helps in the formulation of a degradation prevention strategy which is considered to be the overall goal of degradation studies.

\section{References}

[1] R. J. Nichol and R. H. Sapiro, "Purification of gases," European Patent GB999799, 1965.

[2] R. J. Nichol and R. H. Sapiro, "Purification of gases," European Patent GB999800, 1965b.

[3] R. B. Thompson, "Catalytic removal of hydrogen sulfide from gases," United States Patent US 4189462, 1980.

[4] S. Lynn and B. J. Dubs, "Oxidative removal of hydrogen sulfide from gaseous streams," United States Patent US 4278646, 1981.

[5] Z. Diaz, "Method of removing hydrogen sulfide from gases utilizing a stabilized iron chelate solution," United States Patent US4382918, 1983.

[6] Z. Diaz, " $\mathrm{H}_{2} \mathrm{~S}$ Removal," United States Patent US4388293, 1983.

[7] Z. Diaz, " $\mathrm{H}_{2} \mathrm{~S}$ Removal process," United States Patent US4400368, 1983.

[8] G. C. Blytas, "Method of removing hydrogen sulfide from gases utilizing a stabilized metal chelate solution," United States Patent US4421733, 1983.

[9] S. A. Bedell, "Stabilized chelating agents for removing hydrogen sulfide," United States Patent US4891205, 1990.

[10] D. Chen, R. J. Motekaitis, A. E. Martell, and D. McManus, "Oxidation of $\mathrm{H}_{2} \mathrm{~S}$ to $\mathrm{S}$ by air with $\mathrm{Fe}(\mathrm{II} 1)-\mathrm{NTA}$ as a catalyst: catalyst degradation," Canadian Journal of Chemistry, vol. 71, pp. 1531-1542, 1993.

[11] D. Chen, A. E. Martell, D. McManus et al., "Studies on the mechanism of chelate degradation in iron-based, liquid redox $\mathrm{H}_{2} \mathrm{~S}$ removal processes," Canadian Journal of Chemistry, vol. 73, pp. 264-274, 1995.

[12] D. Mcmanus and F. R. Kin, "Purification of gases," European Patent EP0257124, 1993.

[13] W. Sunda and S. Huntsman, "Effect of $\mathrm{pH}$, light, and temperature on Fe-EDTA chelation and $\mathrm{Fe}$ hydrolysis in seawater," Marine Chemistry, vol. 84, no. 1-2, pp. 35-47, 2003.

[14] A. de Algelis, G. Bellussi, P. Pollesel, U. Romano, and C. Perego, "Process for the removal of hydrogen sulfide, by means of its oxidation in the presence of hetero polyacids," United States Patent US 2007/0178033 A1, 2007.

[15] T. Supap, R. Idem, P. Tontiwachwuthikul, and C. Saiwan, "Kinetics of sulfur dioxide-and oxygen - induced degradation of aqueous monoethanolamine solution during $\mathrm{CO}_{2}$ absorption from power plant flue gas streams," International Journal of Greenhouse Gas Control, vol. 3, no. 2, pp. 133-142, 2009.

[16] L. I. Gautier, P. Bertet, A. Jeunet, G. Serratrice, and L. Louis Pierre, "Iron-citrate complexes and free radicals generation: is citric acid an innocent additive in foods and drinks?" Bio Metals, vol. 20, no. 5, pp. 793-796, 2007.

[17] K. Szentmihályi, A. Blázovics, and P. Vinkler, "Free radical properties of metal complexes," Acta Biologica Szegediensis, vol. 47, no. 1-4, pp. 107-109, 2003.

[18] F. C. Delvecchio, R. M. Brizuela, S. R. Khan et al., "Citrate and vitamin E blunt the shock wave-induced free radical surge in an in vitro cell culture model," Urological Research, vol. 33, no. 6, pp. 448-452, 2005. 

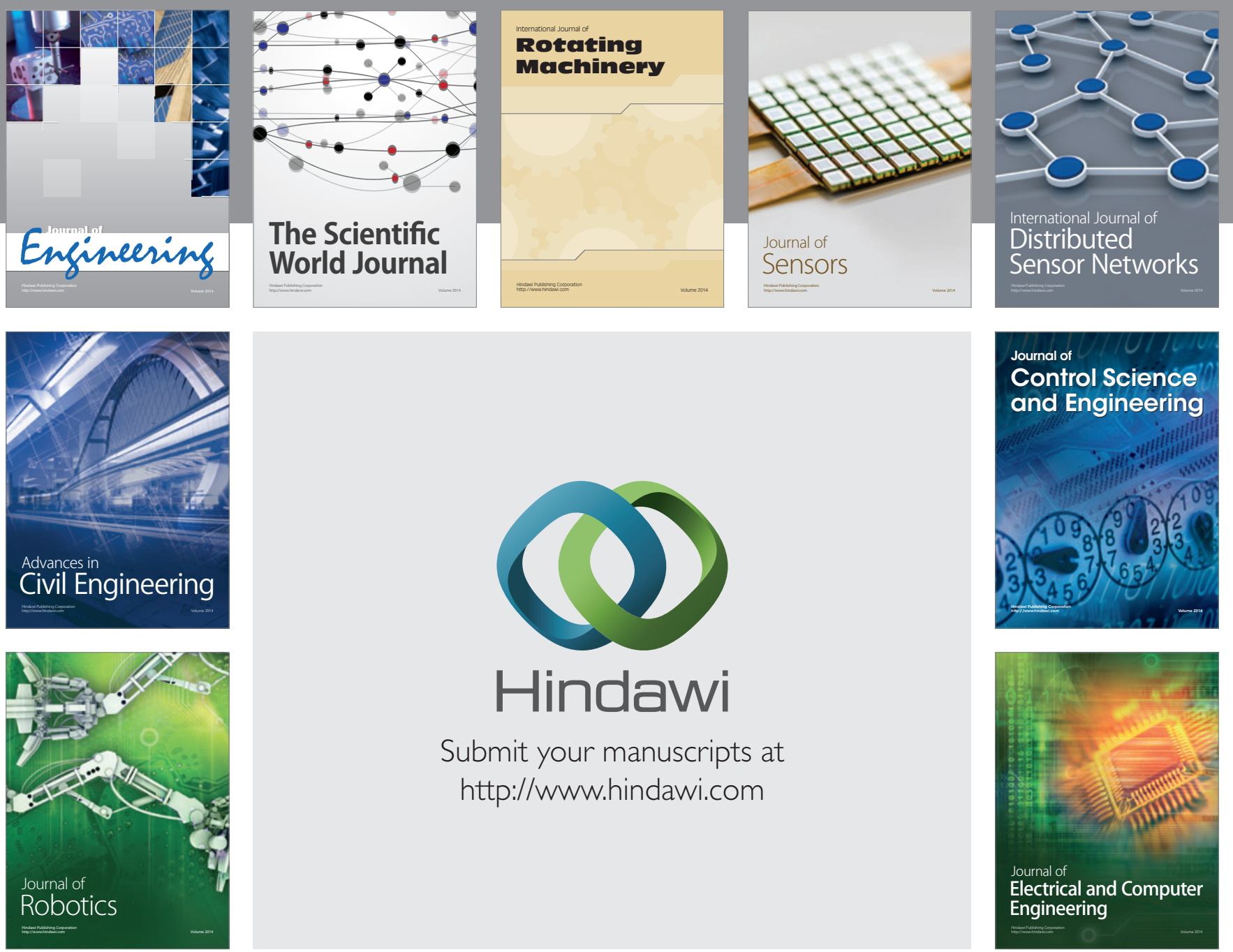

Submit your manuscripts at

http://www.hindawi.com
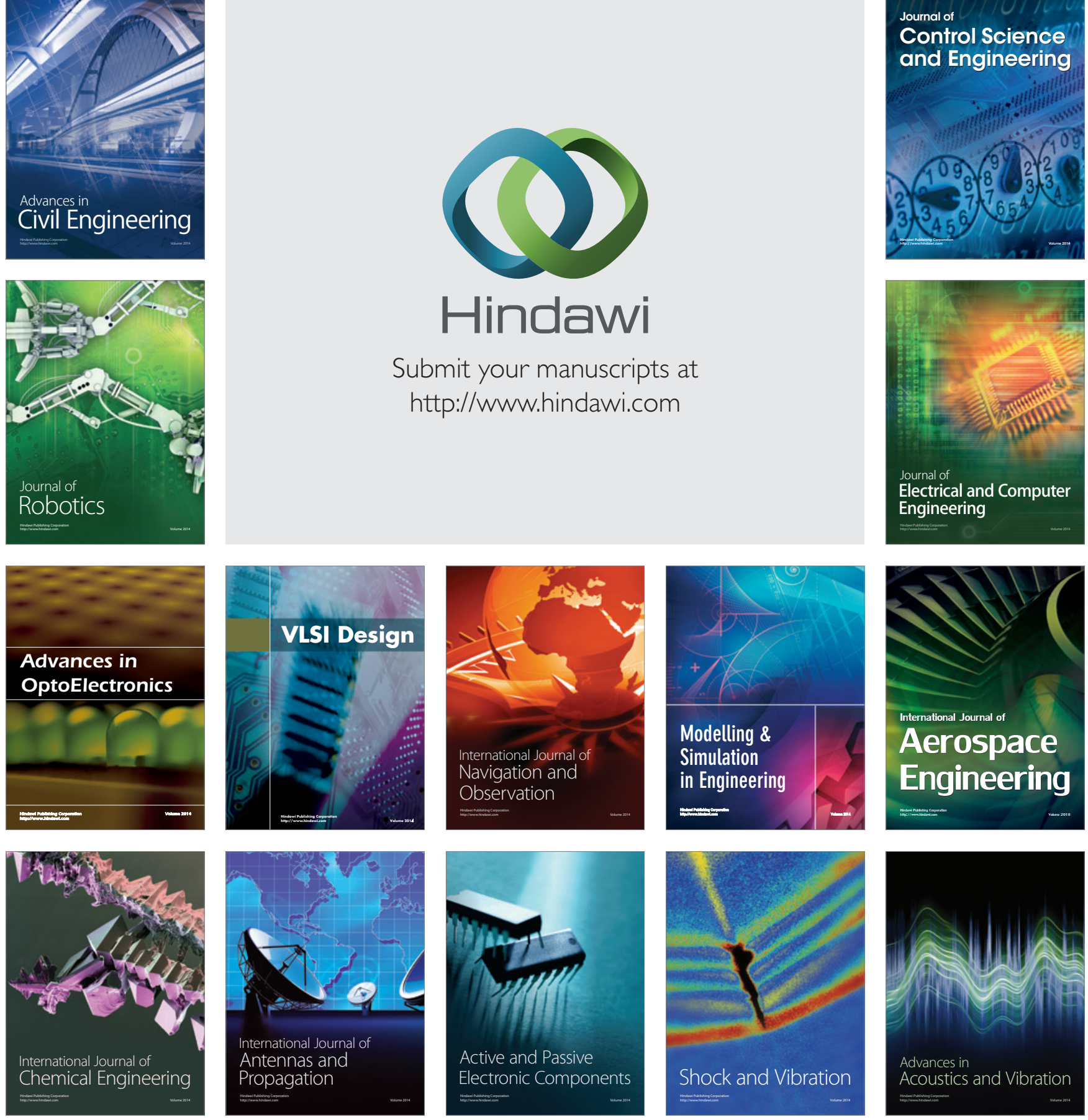